\title{
مصدر الضبط الصحي كمتغير وسيط بين الضغط النفسي والمرض الجسدي
}

$$
\begin{aligned}
& \text { د. أحمان لبنى } \\
& \text { مخبر التطبيقات النفسية في الوسط العقابي }
\end{aligned}
$$

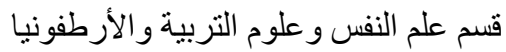

$$
\begin{aligned}
& \text { جامعة باتنة } 1
\end{aligned}
$$

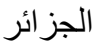

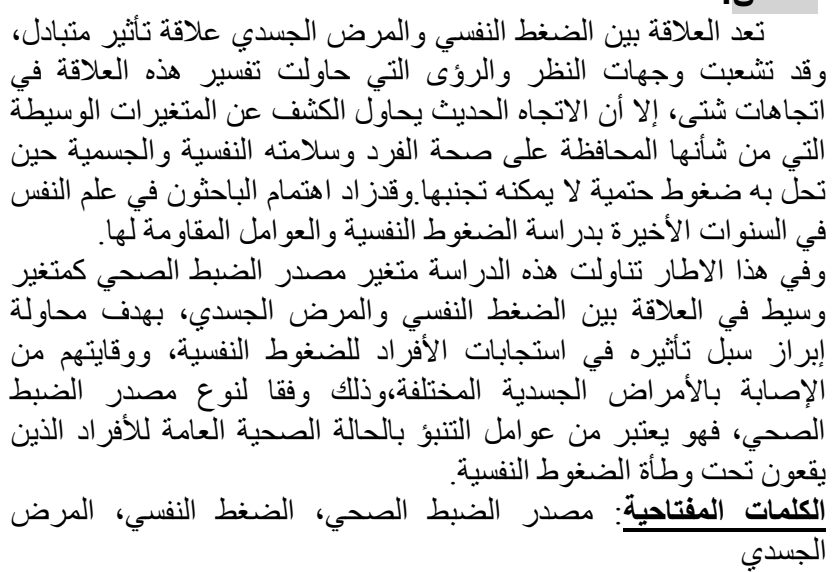

Abstract:

The relationshipbetween stress and physicalillnessrelationship of mutualeffect, has branched out views and visions thatattempted to explainthisrelationship in various directions, but the modern trend tries to detect the intermediate variables thatwillmaintain the health of the individualpsychological and physicalintegrity, whilesolving the inevitable No pressure itcanbeavoided. Researchersinterested in psychology in recentyearsstudying the stress and resistancefactors have increased.

In thiscontext, thisstudydealtwith a locus of control variable and mediator in the relationshipbetween stress and physicalillness, in order to try to highlight the waysits impact on individualresponses to psychological pressures, and to prevent the incidence of variousphysicalillnesses, according to the type of locus of control, itisconsidered to predictfactorsgeneral state of health of individualswho are underpsychological pressure.

Key words: Locus of control, stress, physicalillness 
فعوامل الصحة والمرض لم تعد مقتصرة على العوامل البيولوجية فقط كالإصابة بالفيروسات

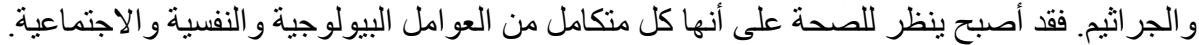

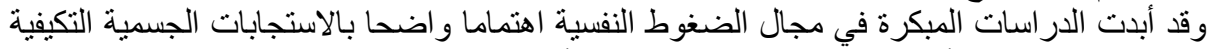

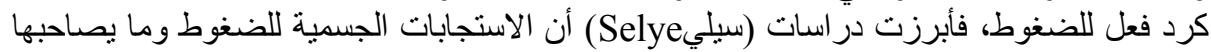

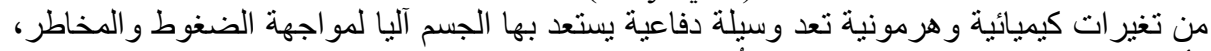

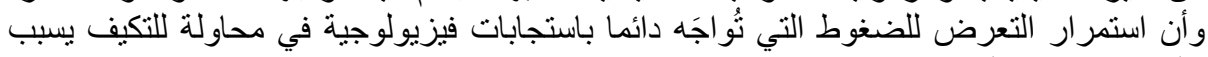

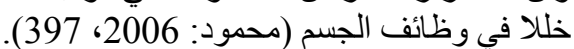

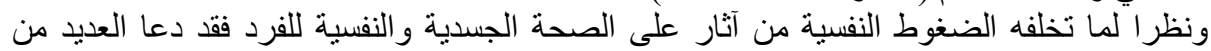

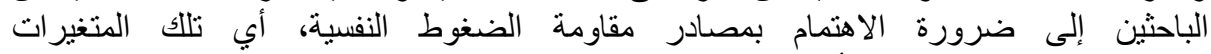

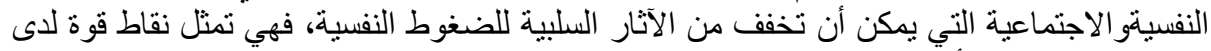

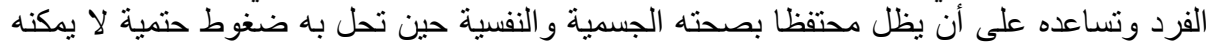

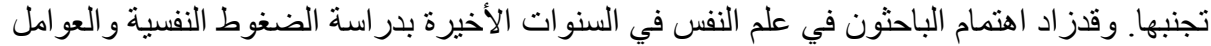

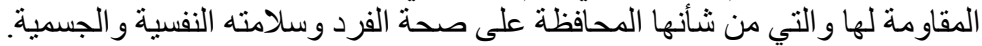

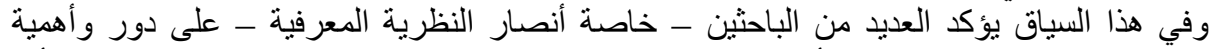

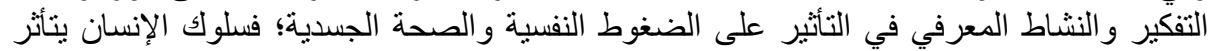

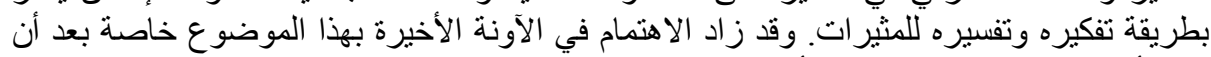

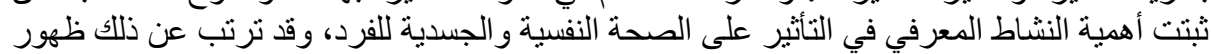

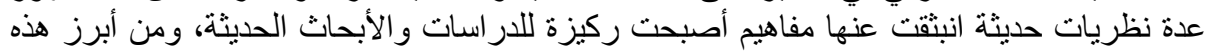

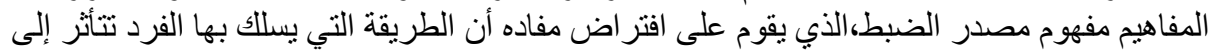

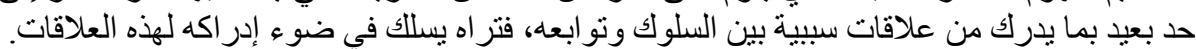

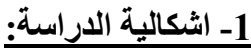

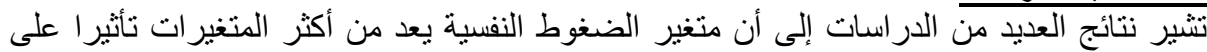

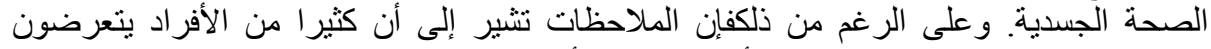

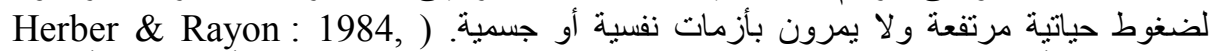

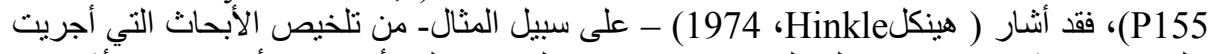

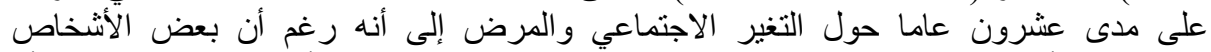

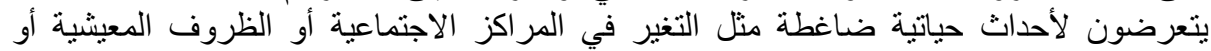

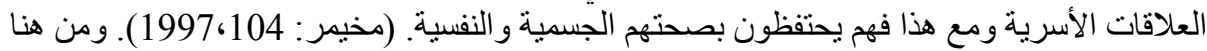

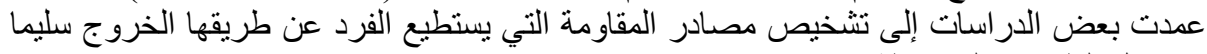
رغم كل الظروف الضاغطة.

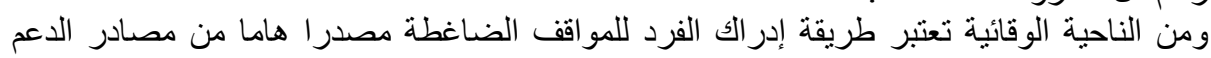

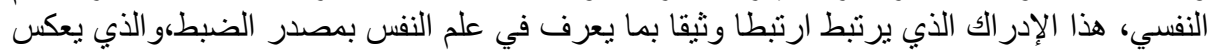

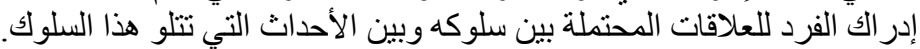
وقد أظهرت نتائج العديد من الدراسات مثل دراسة كل من: (Kobasa, 1979)، ( Fielding \& (Gobbis\& al, 2003)، (Younger, 1995)، (Sarason\& al, 1983) (Y) 1982 (Frazier, 1999) وجود علاقة إيجابية بين التغلب على الضغوط النفسية ومصدر الضبط الداخلي،

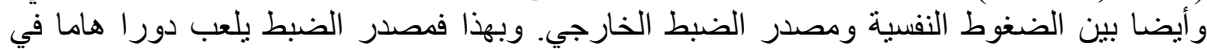
التأثير على النتائج المترتبة عن الضغوط النغوط النفسية.

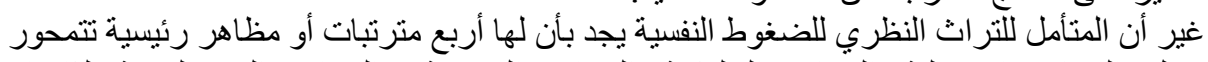

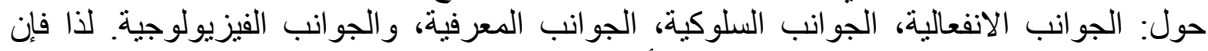

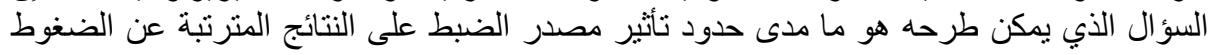


النفسية. وبشكل خاص على الجوانب الفيزيولوجية و التي تعد الدحور الرئيسي للار اسة الحالية. فقد

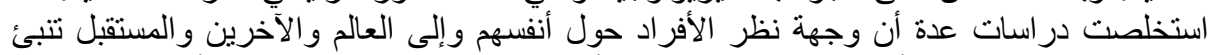

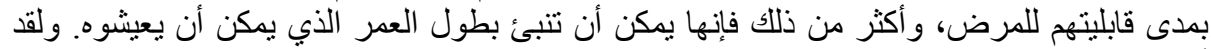

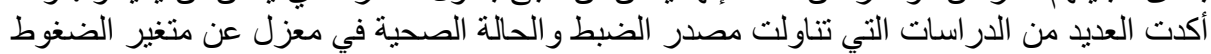

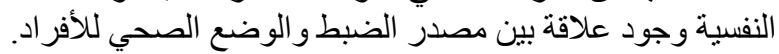

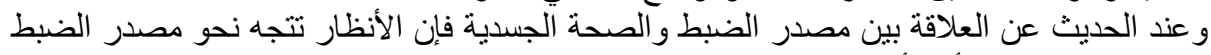

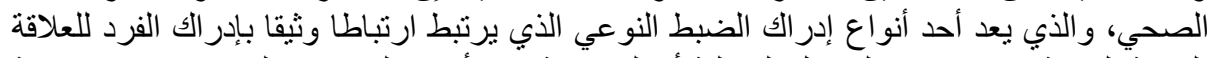

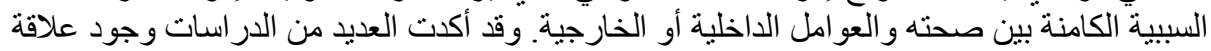

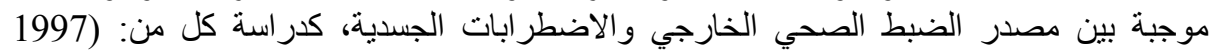
Chung 2005)، (Bruckerte\&Consolis, 2004) (Hobbis\& al, 2003)، (Debra \& al, . \& al, وبهذا تحددت إنثكالية الدراسة وفقا لما سبق في محاولة إبراز تأثثر مصدر الضبط الصحي في العلاقة بين الضغط النفسي و المرض الجندي.

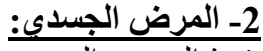
يتخذ المرض الجسدي ثناثة أثنكال رئيسية، والتي تلتمثل في:

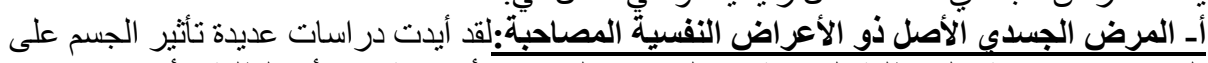

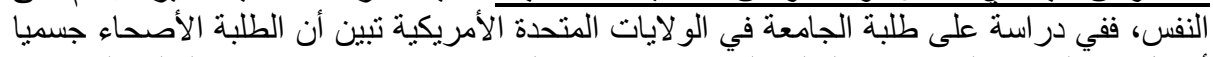

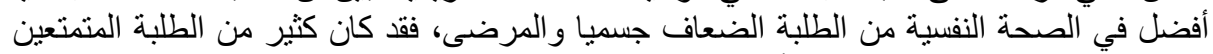

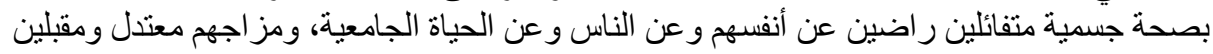

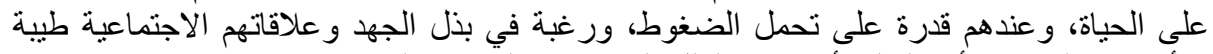

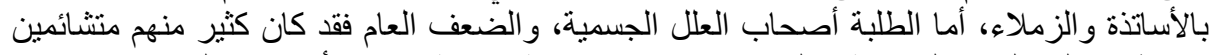

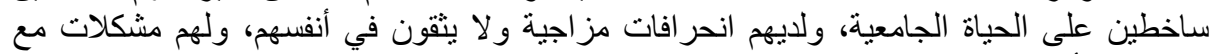

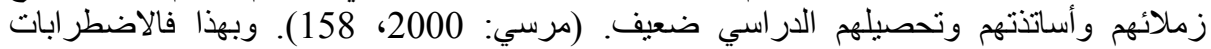

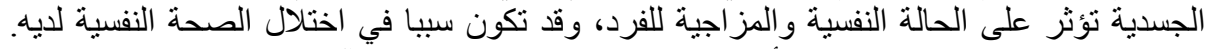

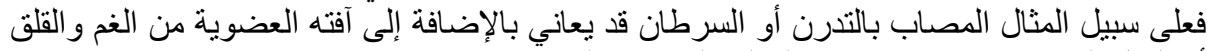

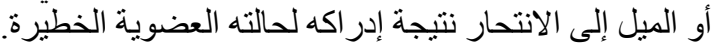

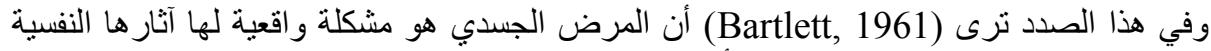

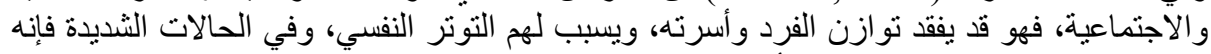

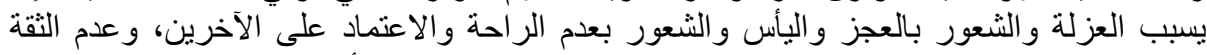

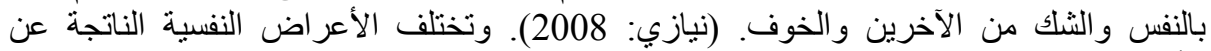

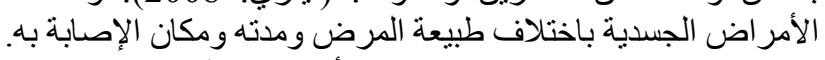

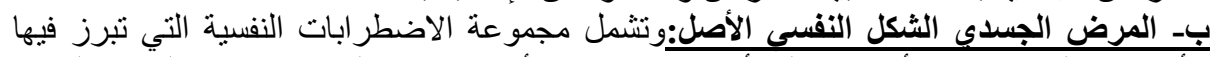

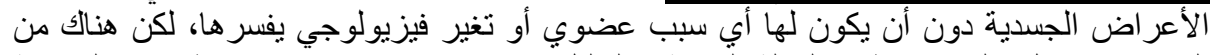

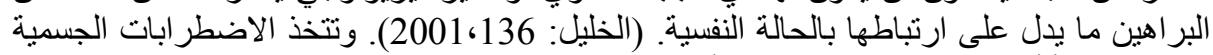
النفسية المنشأ أثنكالا مختلفة، يمكن إيجاز أهمها فيما يلي: الفئية $\checkmark$

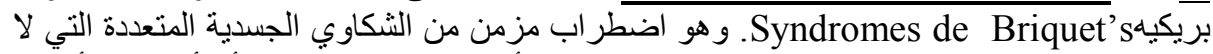

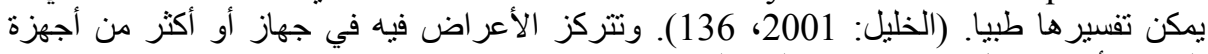

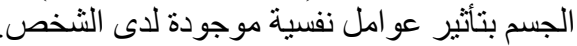

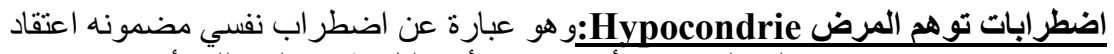

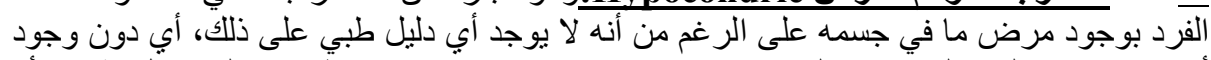

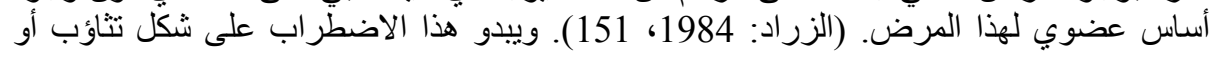




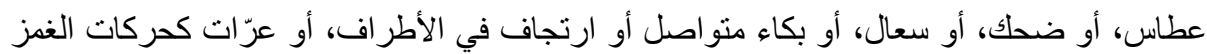

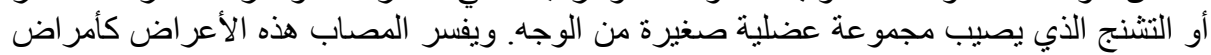

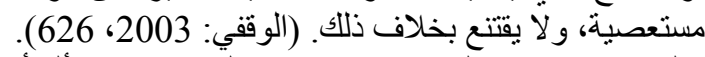

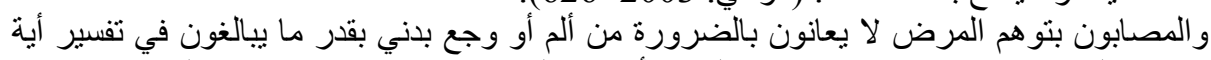

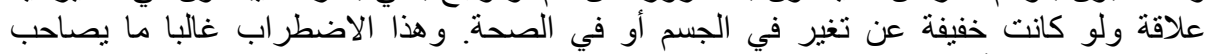
اضطر ابات نفسية أخرى لاسيما القلق و الاكتئاب.

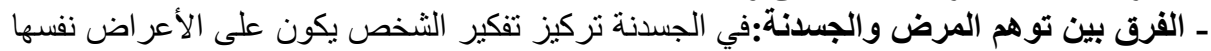

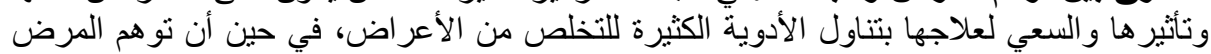

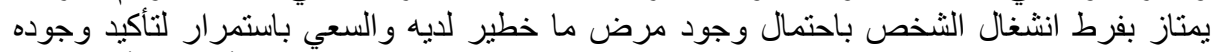

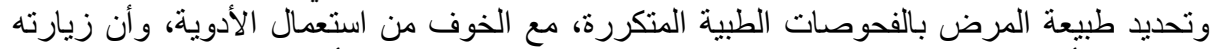

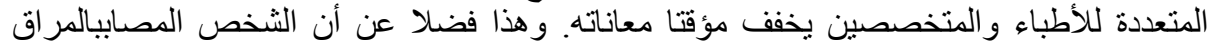

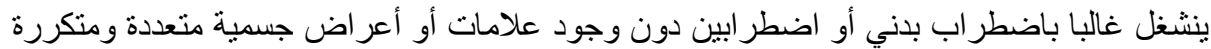

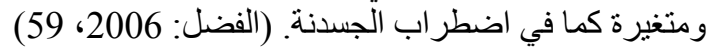
لـ

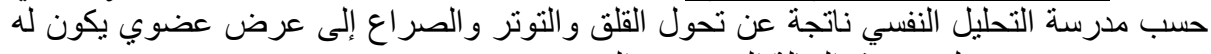

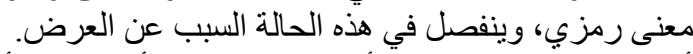

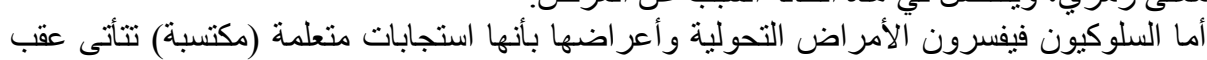

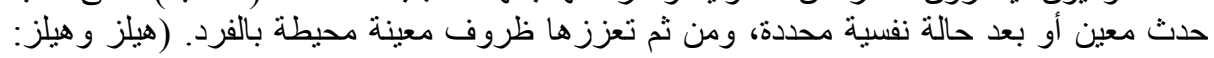

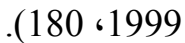

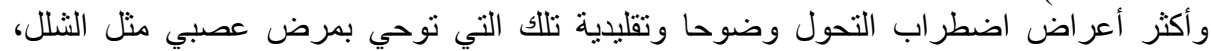

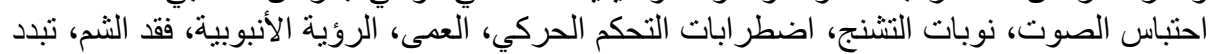

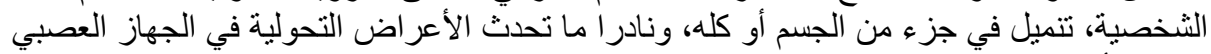

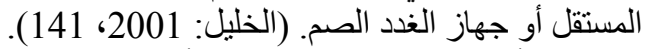

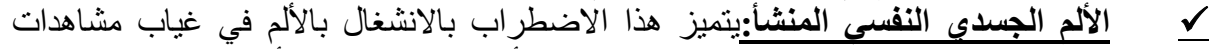

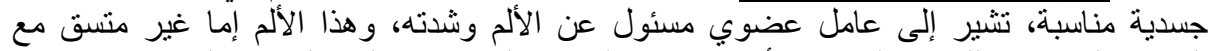

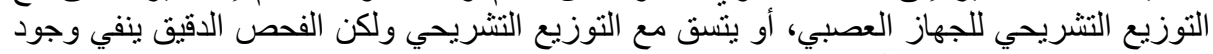

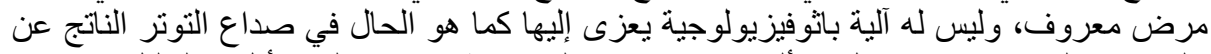

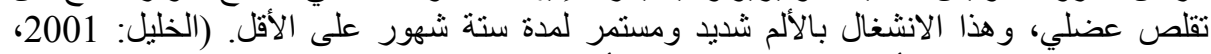
146).ويتخذ أضطر اب الألم الجسدي النفسي الالميدي المنشأ شكلان رئيسيان:

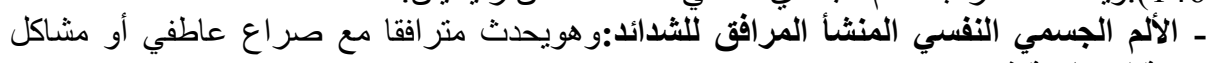

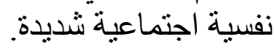
ـ الألم الجسمي النفسي المنثأ وغير المرافق للثدائد:لا ترافقه مباشرة عو امل نفسية واضحة أو حادة

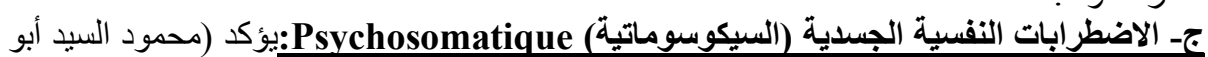
النيل،1997) أن الجسم يؤثر في النفس كما تؤثر النفس النفس في الجسم، وينشأ عن ذلك التأثير الأخير ما

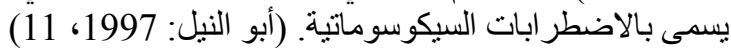

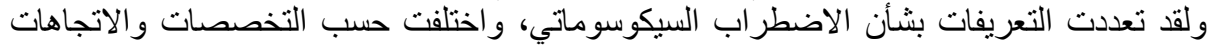

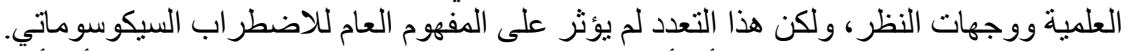

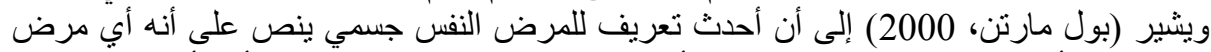

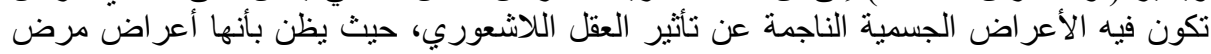
عضوي، لذلك فإن الفرد المريض يلتمس لها في هذه الحالة علاجا طبيا عضويا. (مارتن: 2000، 
ويمكن تعريفها بأنها تثير إلى كل الاضطر ابات الجسمية التي يلعب فيها العامل النفسي الانفعالي دور التها

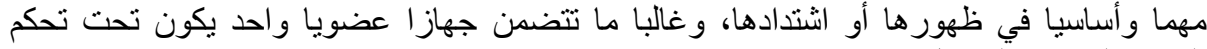

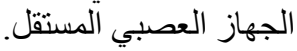
ـ الفرق بين الاضطر ابات النفس جسدية وكل من الجسدنة و الاضطر ابات التحولية:

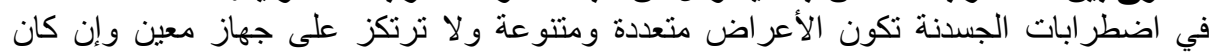

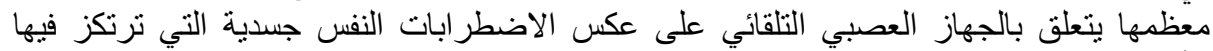
الأعر اض على جهاز معين يتعلق بالجهاز العصبي التلقائي.

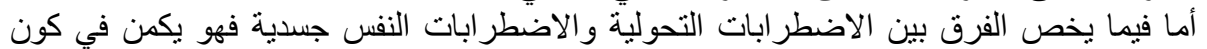

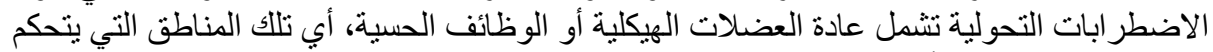

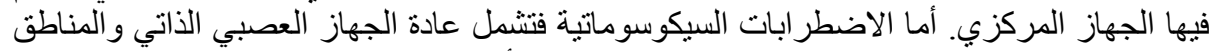

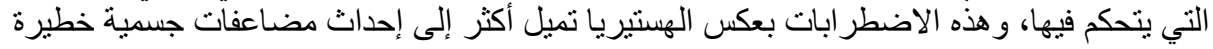

ومميتة. (موسى: 2001، 201، 291).

3- الضغط النفسى:

يشير مفهوم الضغوط النفسية Stress إلى الاستجابات غير النوعية لمثيرات مختلفة بالغة القوة،

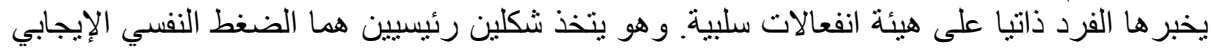

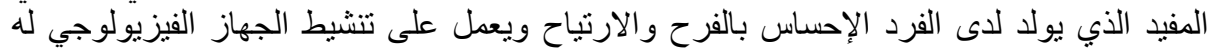

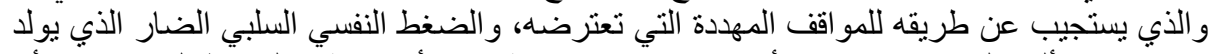

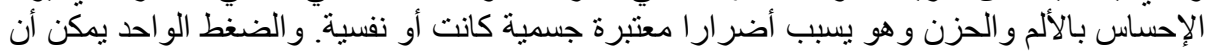

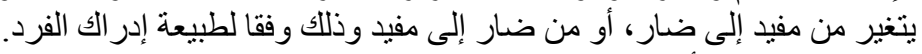

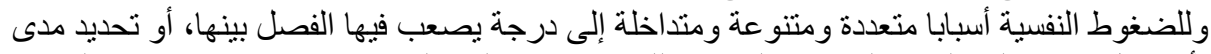

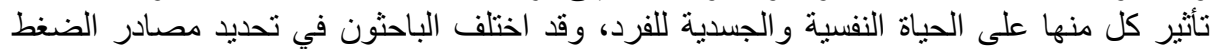

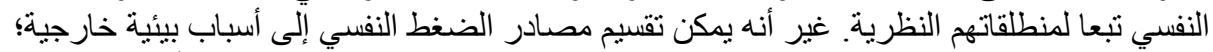
و التي تتمل كل المثير ات الفيزيقية والاجتماعية الموجودة في النية البيئة المحيطة بالفرد، و وأسباب داخلية؛

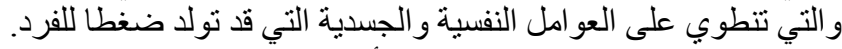

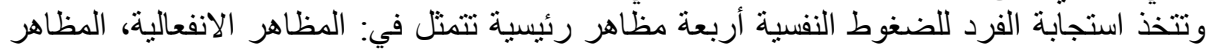

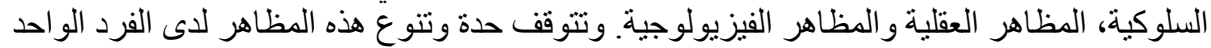

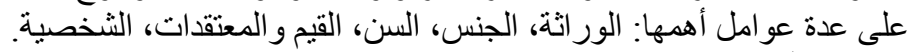

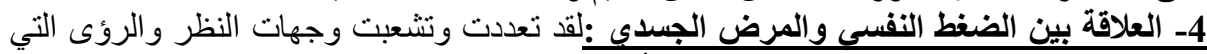

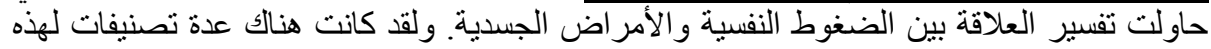

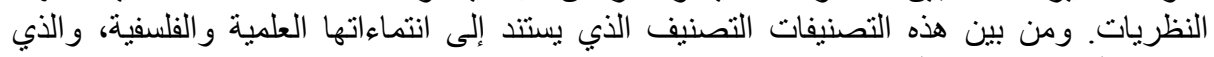

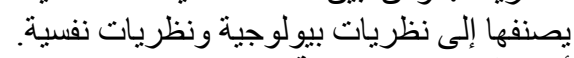

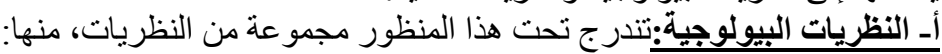

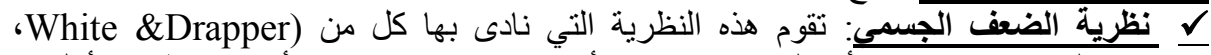

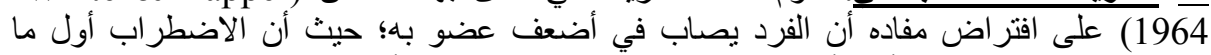

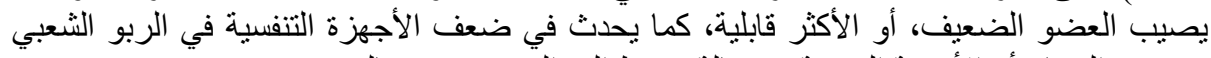

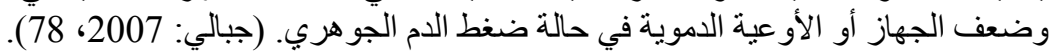

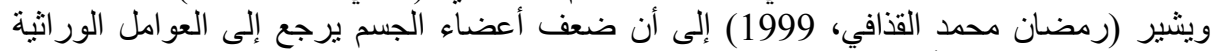

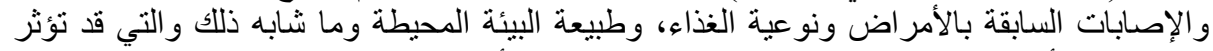

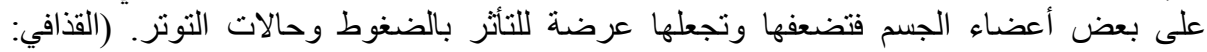

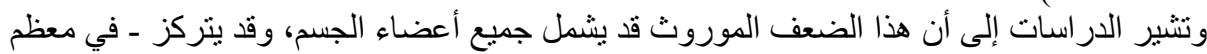

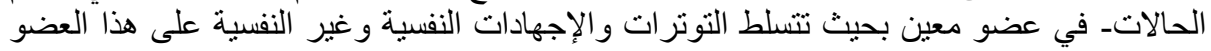


الضعيف فتضعفه، وقد يؤدي ذلك بهذا العضو إلى الاضطراب الوظيفي أو المرض السيكوسوماتي.

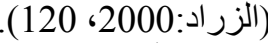

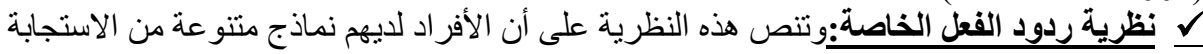

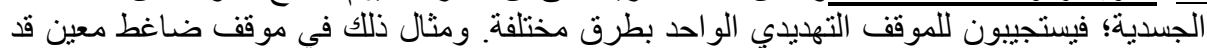

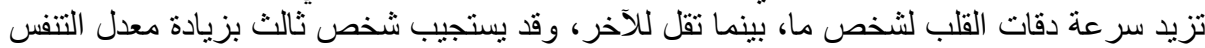
ونجا أي تغير ات تذكر في دقات القلب.

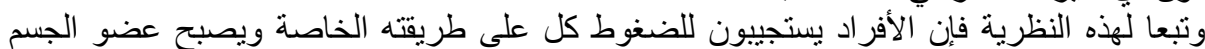

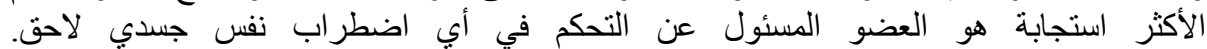
(Davison\&Neale: 1996, P200)

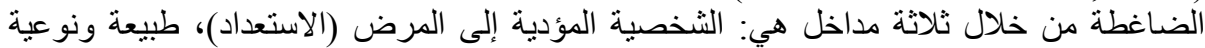

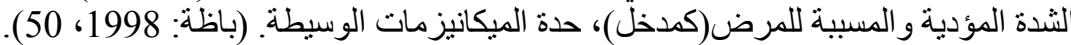

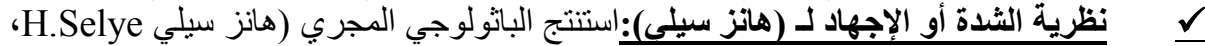

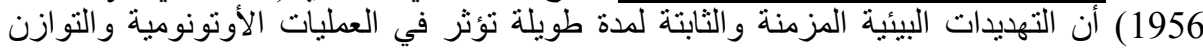

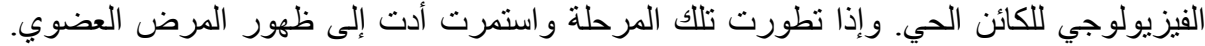

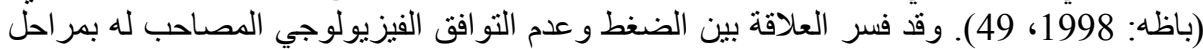

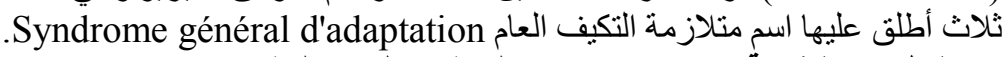

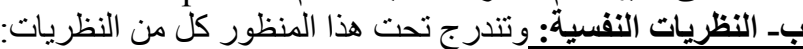

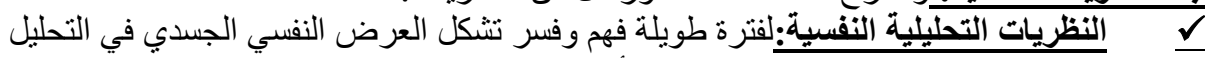

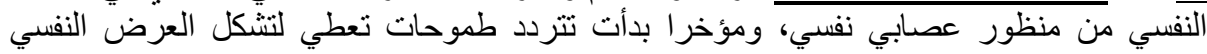

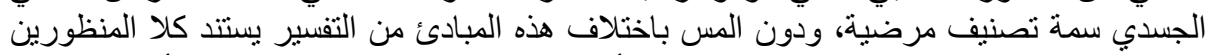

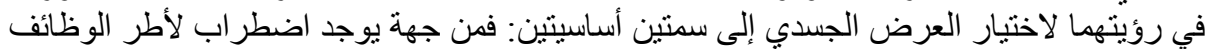

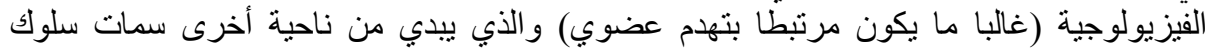

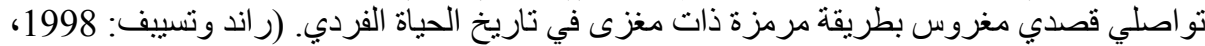
77). وسيتم فيما يلي إيجاز بعض النظريات التحليلية النفسية التي حاولت تلفيلة تفسير ظهور الأمراض

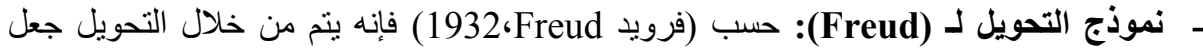

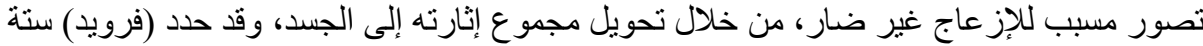
سمات للعرض التحوي ليلي نفسه: ـ ينشأ العرض التحويلي عندما تنزلق رغبة دافع في صراع مع المعايير الاجتماعية والداخلية وتقود

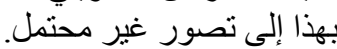
ـ ـ والتي لابد لها لهذا من أن تُبتعد عن الثعور. - والصراع من طبيعة جنسية تناسلية (أوديبي).

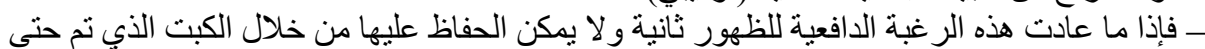

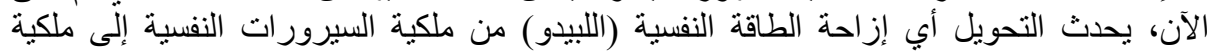

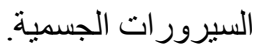

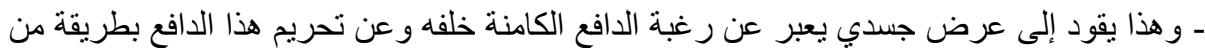

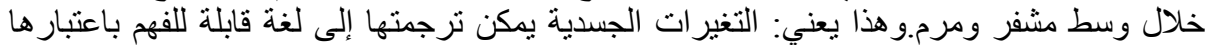

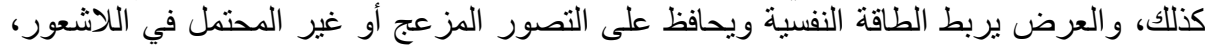

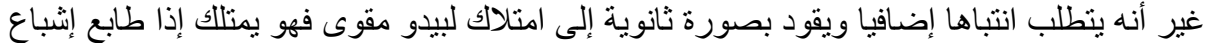
وطابع عقاب في الوقت نفسه. 
مصدر الضبط الصحي كمتغير وسيط بين الضغط النفسي والمرض الجسدي

- وقد تمسك (Freud) بأنه ينبغي التسليم بوجود تساهل جسدي أي عامل جسدي يمتلك أهمية فيما

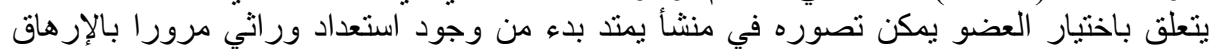

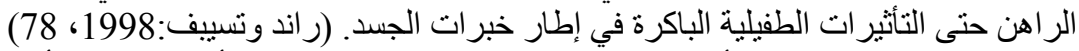

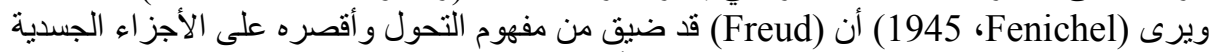

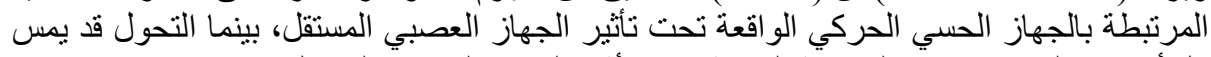

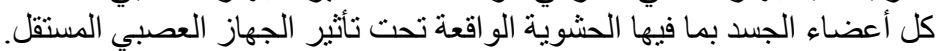

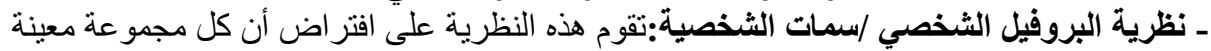

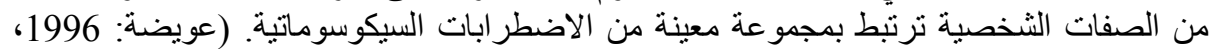

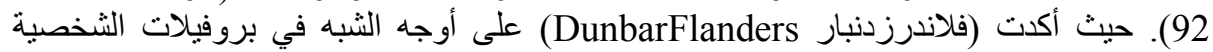

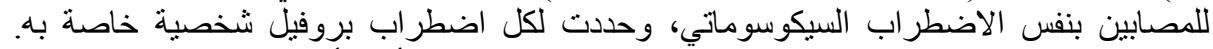

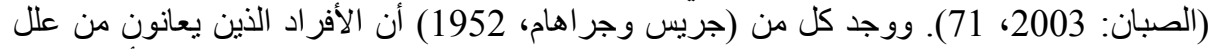

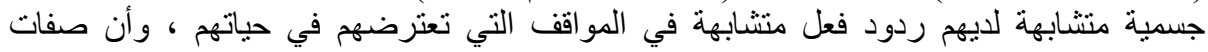

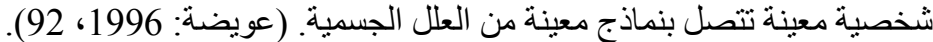
وترى (دنبارمunbar) أن بإمكان المرض من أن يكون ذا منشأ داخلي، كما يمكن أن يكون ـ أيضاـ ذا ذا

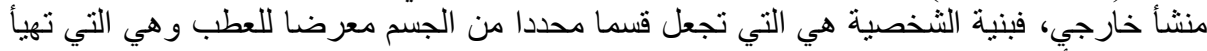

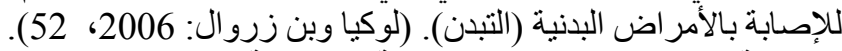

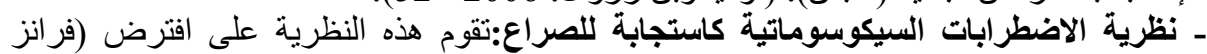

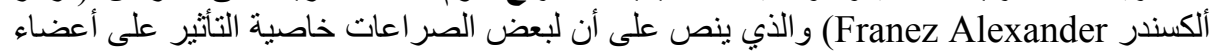

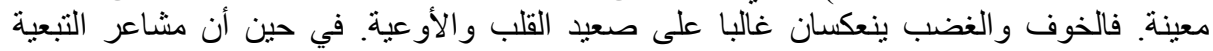
والحاجة للحماية ينعكسان غالبا على صعيد الجهاز الهضمي. (النابلسي ومارتي في وستورا: 1992،

ويؤكد (Alexander) على أن الصراعات الحالية ترجع إلى صراعات لاشعورية رمزية مرتبطة

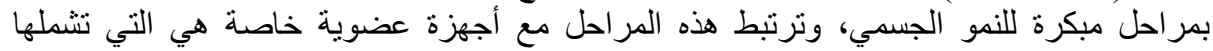

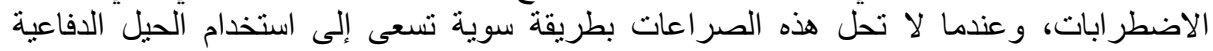

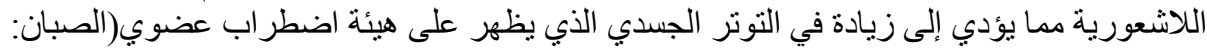

ـ نظرية النكوص:يرى كل من (Michaels, 1944) و(Szasz, 1952) أن العرض السيكوسوماتي

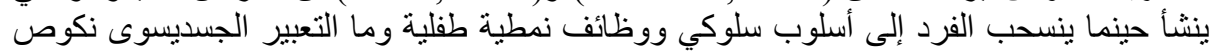

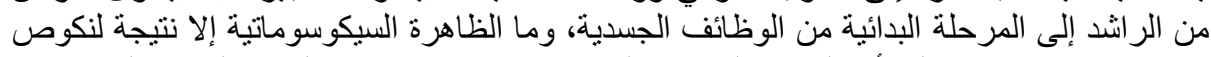

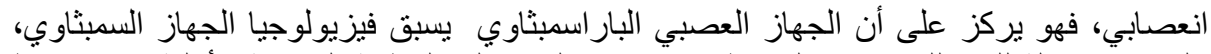

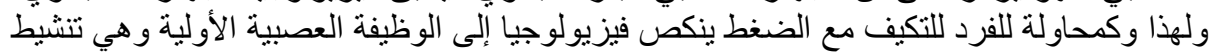

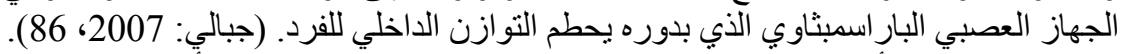

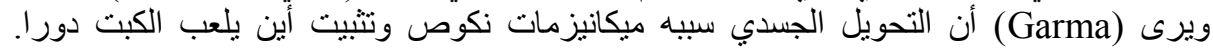

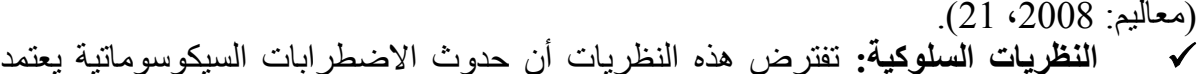

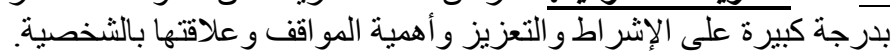

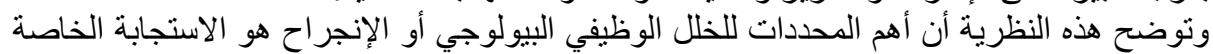

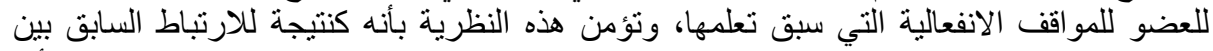

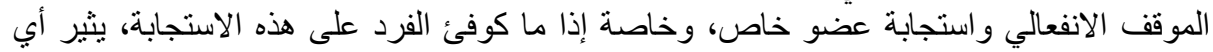

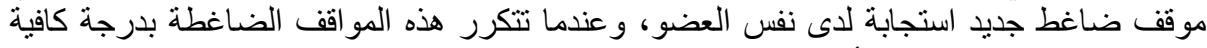
وشديدة يظهر الخلل الوظيفي أو الإنجراح في هذا العضو. (عويضة: 1996، 85). 
وفي أو اخر الستينات صارت هذه النظرية تؤمن بإمكانية التحكم في استجابات الجهاز العصبي المستقل

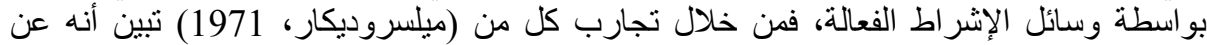

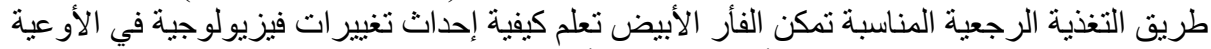

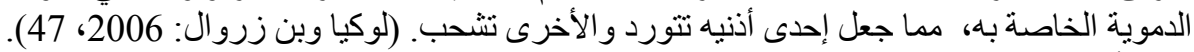

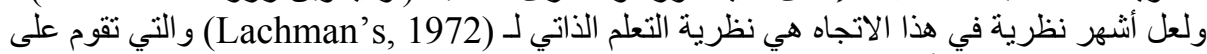

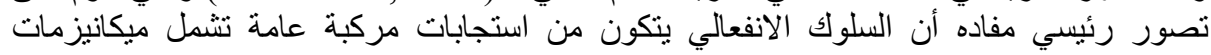

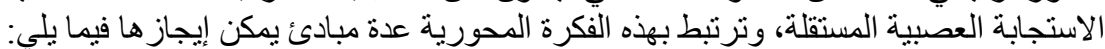

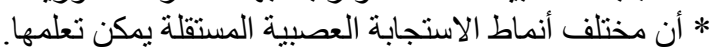

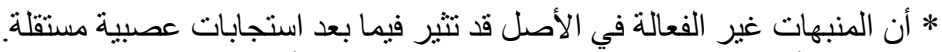

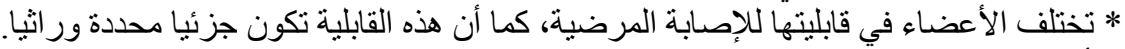

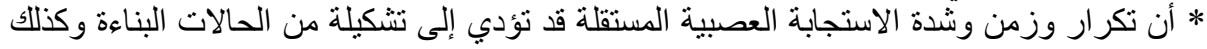

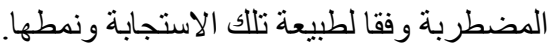

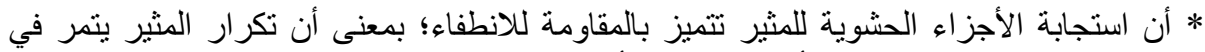

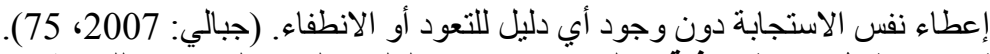

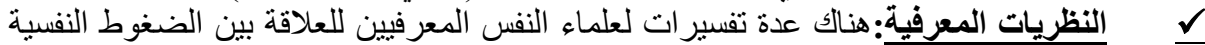

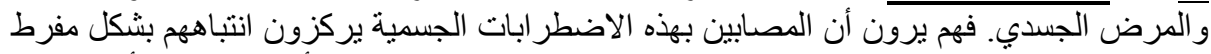

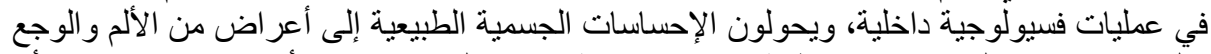

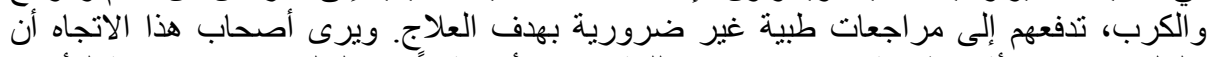

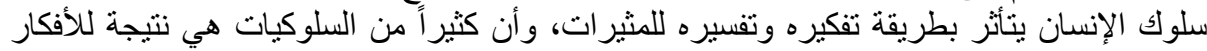
غير العقلانية، ويمكن تعديلها من خلال التخان التغيير في التفكير.

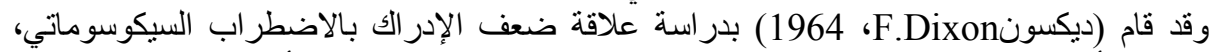

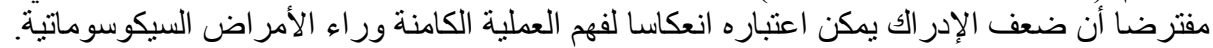

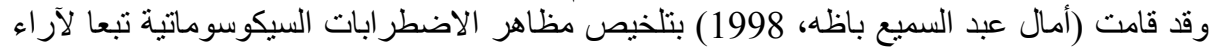

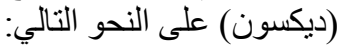

* ت تتسبب الضغوط على النفسية في مجمو عة و اسعة من الأعر اض الجسدية. * تفترض طبية هذه الأعراض توسط طرق عدئ عديدة للنقل المبانشر للجهاز الأوتونومي والأجهزة

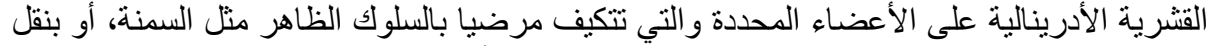

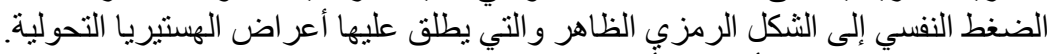

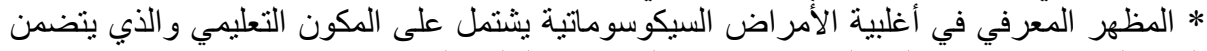

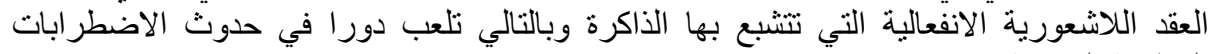

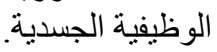

* مفهوم بعض الاضطرابات السيكوسوماتية يتضمن المكون العقلي أو المعرفي لطبيعة العلاقة

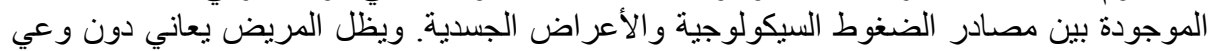

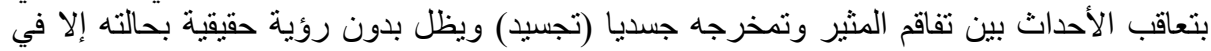

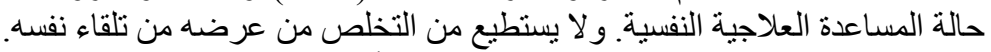

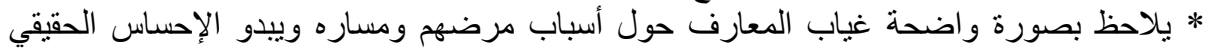
بتعاقب التهيد للعاطفة السالبة الناتجة عن الاضطر اب الجسدي. (باظة الطه: 1998، 51). 5- مفهوم مصدر الضبط الصحي:

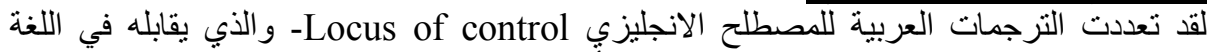
الفرنسية مصطلح lieu de contrôle - وذللك لنشأته في بيئة لغوية وتثقافية غربية فترجم مثلا: مركز التحكم، موضع الضبط، مصدر التحكم، وجهة التحكم، وجهة الضبط، محل التبعة. 


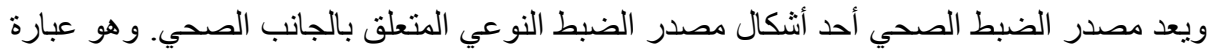

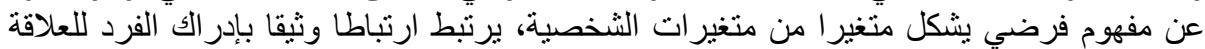

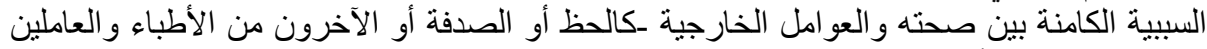

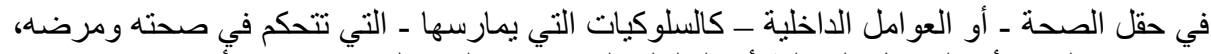

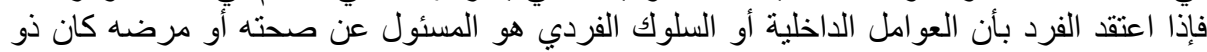

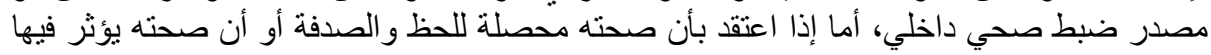
الآخرون كان ذو مصدر ضيط ضيط صحي خارجي.

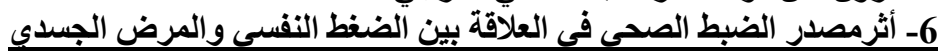

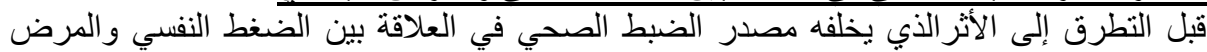

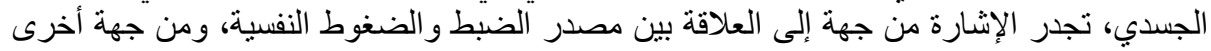

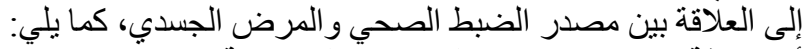

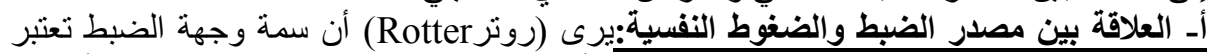

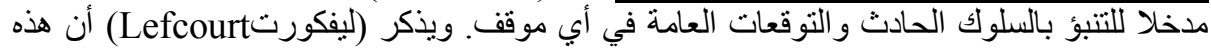

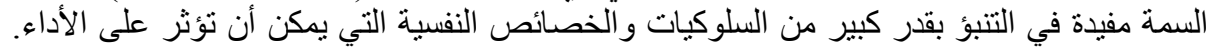
(الذواد: 2003، 122). وبهذا فصصدر الضبط يعد من الهتغيرات المعرفية الهامة في التنبؤ بمستوى الأدى الضغوط النفسية و إدر اكها. ويكمن الأساس المعرفي لمفهوم الضبط في علاقته بالضغوط في توقعات الفرد عن قدرته على التدكم

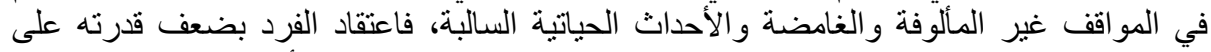

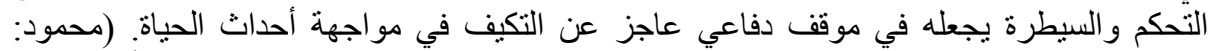

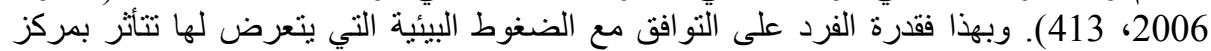

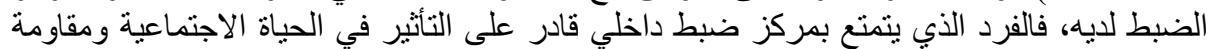

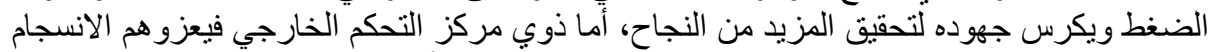

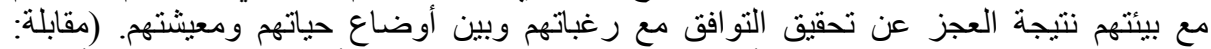

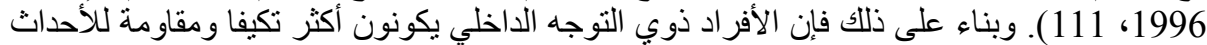

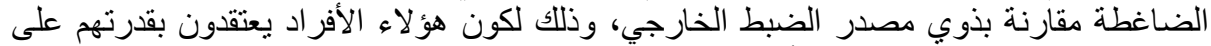

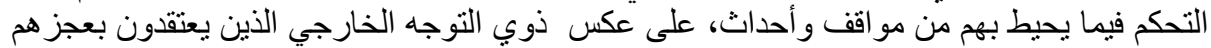
عن التحكم فيما يحيط بهم من مو اقف و وأحداث.

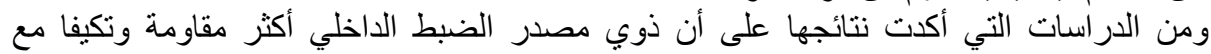

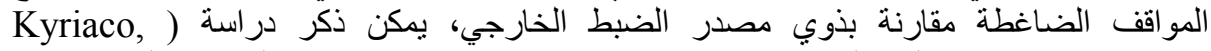
(1979\&Sutcliffe

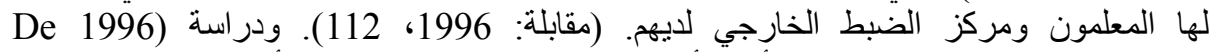
(Brabander\& al,

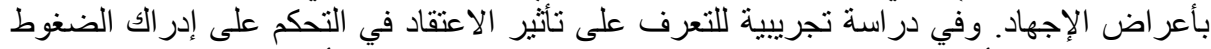

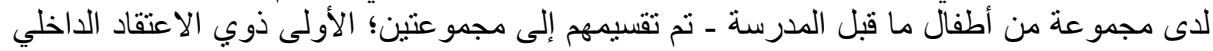

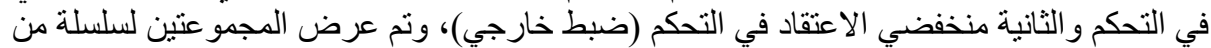

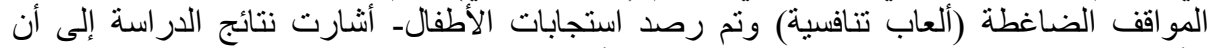

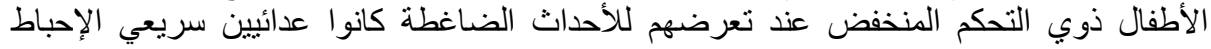
و الاستسلام، ولديهم مشاعر اكتئابية. واتسمت مجموعة التهة الضبط الداخلي (التحكم المرتفع) بالمثابرة.

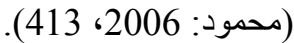

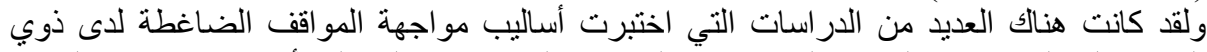

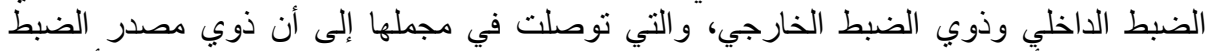

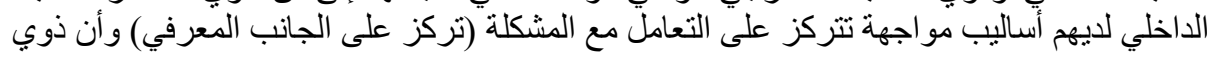


مصدر الضبط الخارجي لديهم أساليب مواجهة غير تكيفيه للاستجابة مع المو اقف الضاغطة تتمثل في الإني

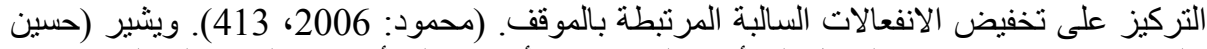

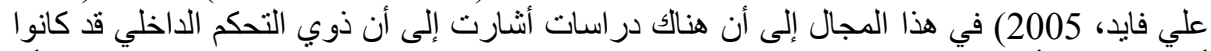

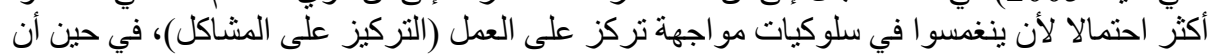

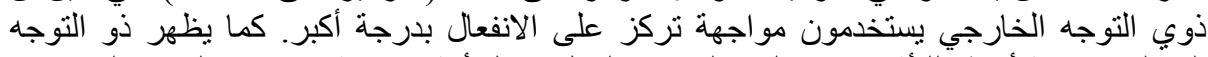

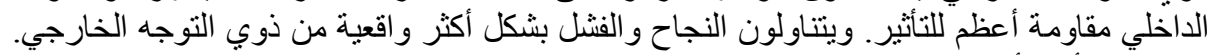

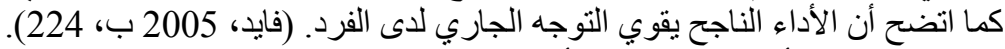

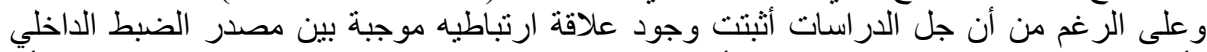

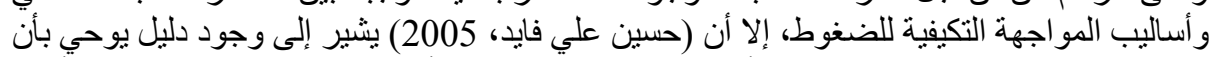

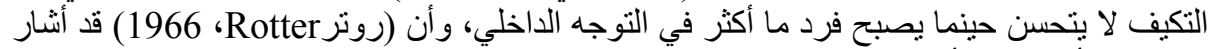

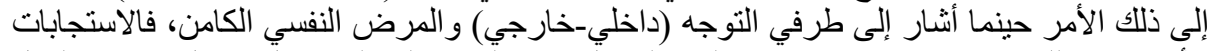

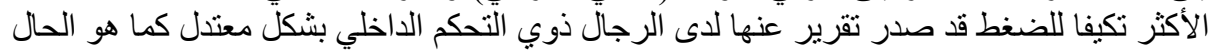

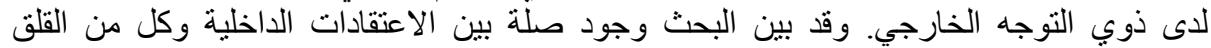

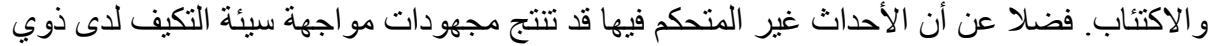

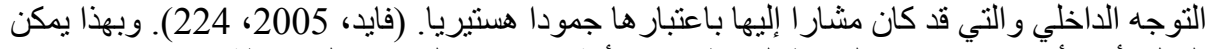

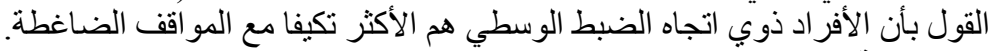

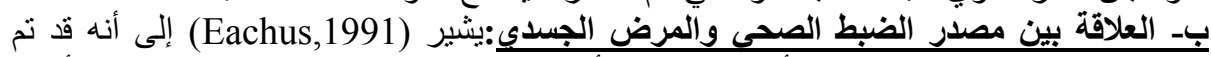

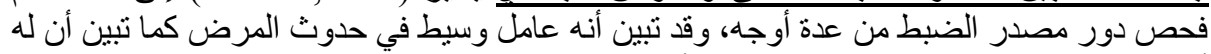

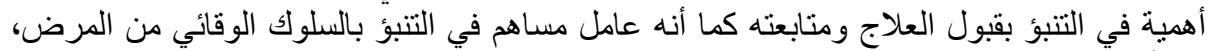
كما أنه عامل دال في السلوك التفاعلي بين المريض النه والمشتئغلين في المجال الصحي. (جبالي: 2007،

وبهذا فمصدر الضبط الصحي يلعب دورا هاما في الوقاية أو الإصابة بالأمر اض الجسدية المختلفة،

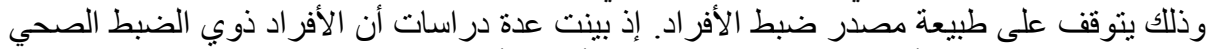

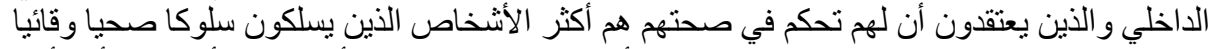

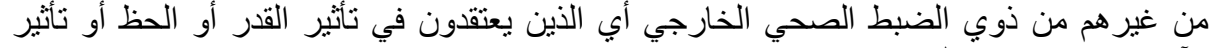
الآخرين في مسار هم الصحي.

ولقد كانت هناك العديد من الدراسات التي تناولت العلاقة بين السلوك الصحي ومصدر الضبط الصبط

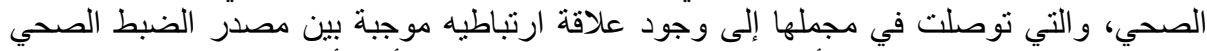

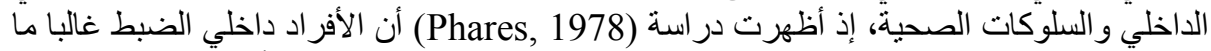

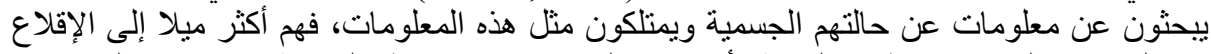

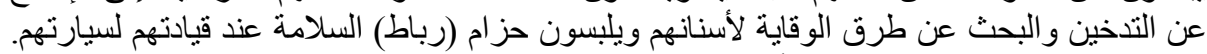

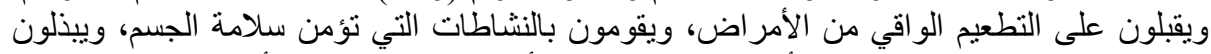

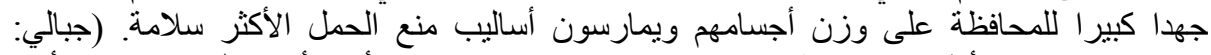

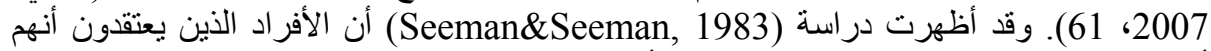

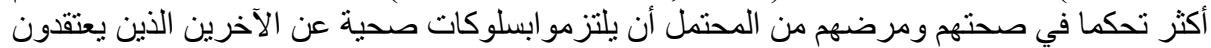

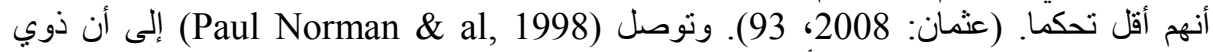
مصدر الضبط الداخلي منقادون أكثر للسلوك الصحي. ( Norman \& Bennett \& Smith \&

.(Murphy : 1998 B, P180

هذا، ويلعب مصدر الضبط الصحي دورا هاما في تقبل أو رفض العلاج، إذ أظهرت در اسة ( (AnderaArmstrong, 2007 وأن ذوي مصدر الضبط الصحي الداخلي تكون حالتهم الصحية جيدة. ويذكر (حسين علي فايد، 2005).أن الدراسات قد أنشارت إلى أن الأفراد ذوي الضبط الداخلي أكثر 
احتمالا لأن ينغمسوا في المعلومات الخاصة بالمرض و المحافظة على الصحة. (فايد، 2005 ب،

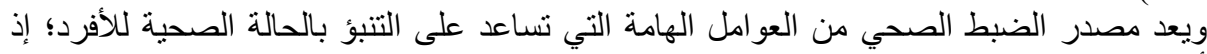

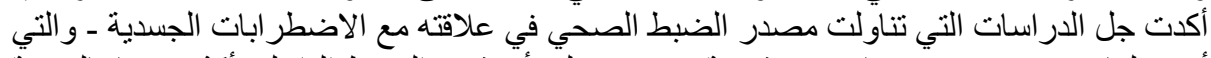

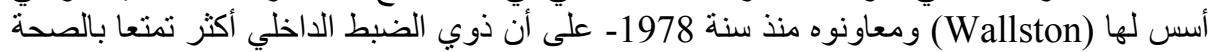
الجسدية وأقل إصابة بالأمراض. ومن بين هذه الدراسات يمكن ذكر: - Nemcek,1990) Younger\& al, 1995 - Vinck\&Valk, 1996 - Gregg \& al, 1996 - Debra \& al, .(1997 - Kennedy \& al, 1999 - Frazier, 1999

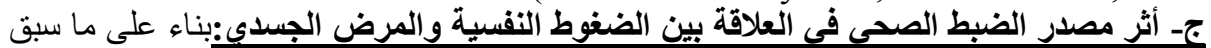

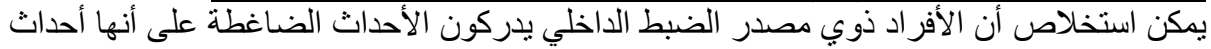

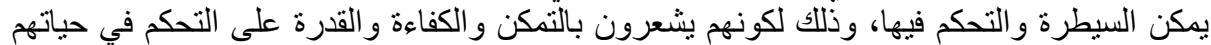

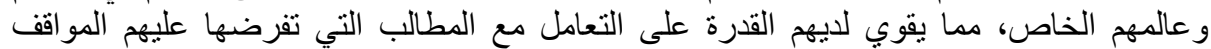

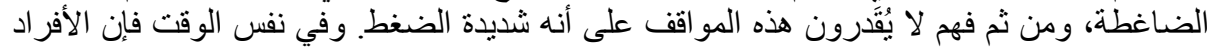

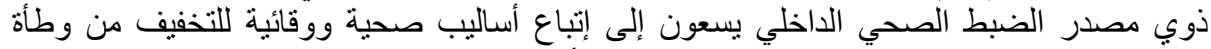
الضغوط بهذف الحفاظ على صحتهم، لاعتقادهم بأن سلوكهم الفردي هو المسئول عن صحتهم

أمـا بالنسبة للأفر اد ذوي مصدر الضبط الخار جي فه يدركون الأحداث الضاغطة على أنها أحداث

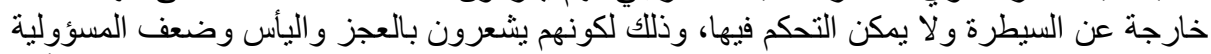

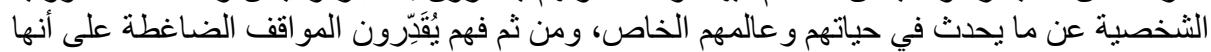

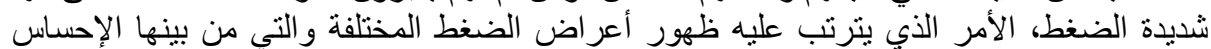

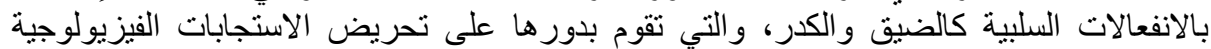

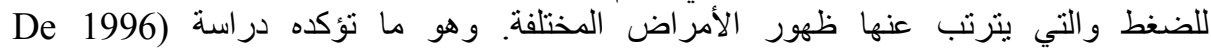
(Brabander\& al, بأعر اض الضغط.

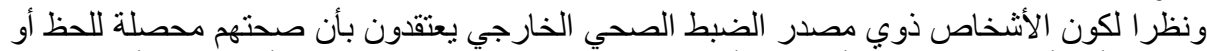

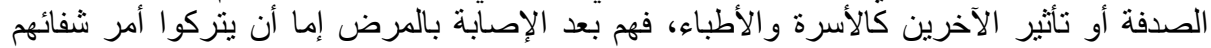

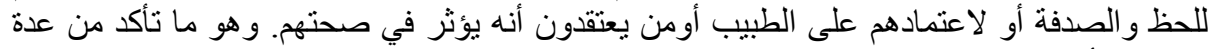

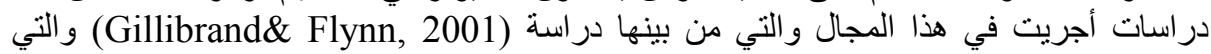
هدفت لوصف وكثف العلافة بين إدر الك المصابين لمصدر الضبط الصحي لديهم و الإصابة بالسكري،

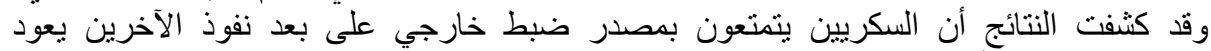

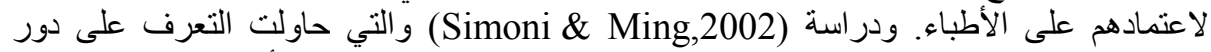

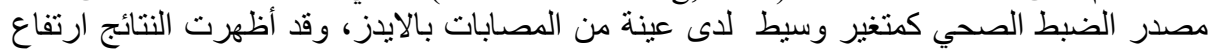

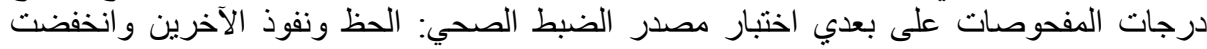

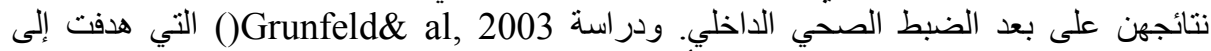

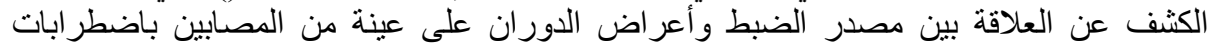

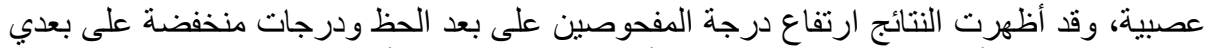

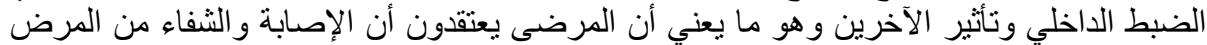

مسألة حظ.

خاتمة:

لقد تعددت وتشعبت وجهات النظر والرؤى التي حاولت تفسير العلاقة بين الضغوط النفسية

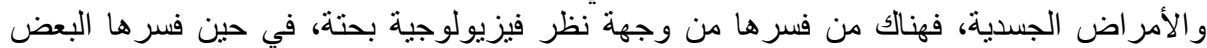

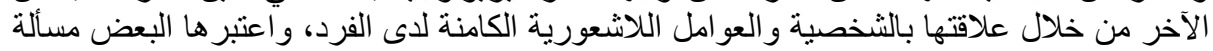


تعلم شرطي يحدث عن طريق تعميم المثير أو تعزيزه، كما ربط البعض الآخر بين العمليات المعرفية العزية

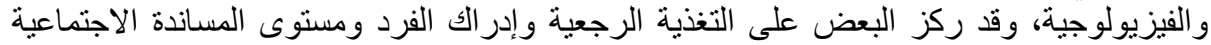
المقدمة لله وإمكاناته الذاتية.

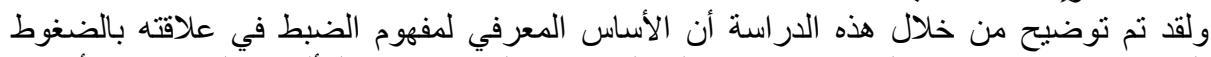

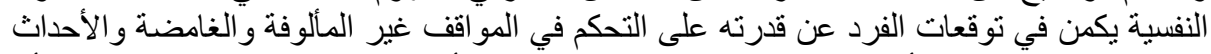

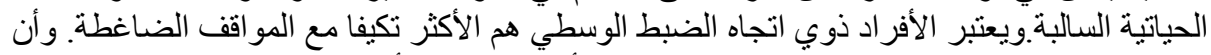

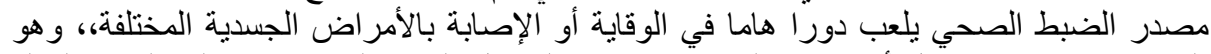

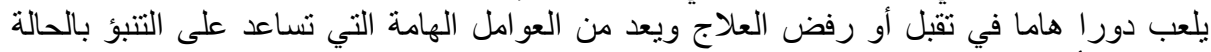

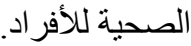

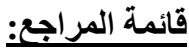

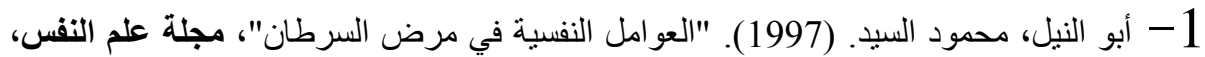
العدد 43، السنة 11. مصر : الهيئة الدصرية العامة للكتاب. ص صلفية فرض- 29.

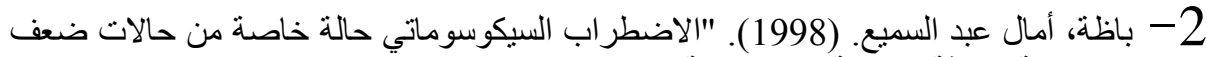
الإدر الك"، مجلة الثقافة النفسية المتخصصة، المجلد: 9. 9، العدد: 34. طر ابلس، لبنان: مركز الدراسات حات النفسية و النفسية الجسدية، ص 49- 53.

3- تايلور، شيلي. (2008). علم النفس الصحي، ط 1، نرجمة ودة وسام درويش بريك وفوزي شاكر داود. عمان - الأردن: دار الحامد للنشر و التوزيع النغي،

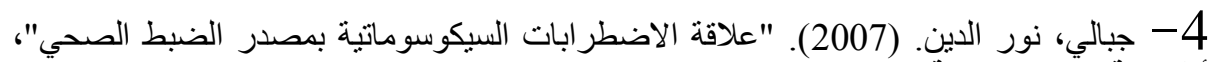

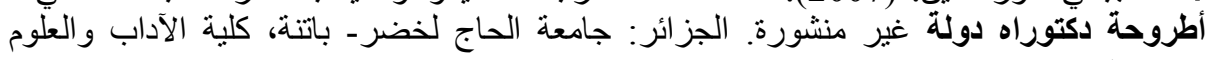
الإنسانية.

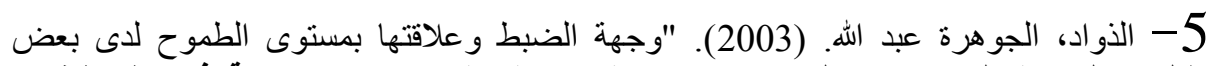
طالبات الجامعة السعوديات والمصريات: داندات دراسة عبر ثقافية"، دراسات عربية في علم النفس، المجمو عة1، العدد: 3. القاهرة. ص صل الع 119-156.

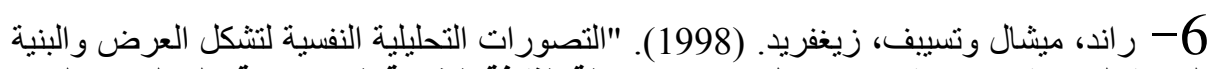

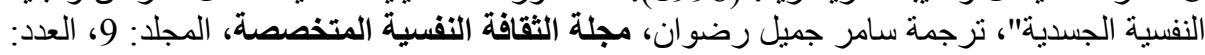
35. طر ابلس- لبنان: مركز الدراسات النفسية و النفسية الجسدية. ص 77 - 103.

7- الزر اد، فيصل محمد خير. (1984). الأمراض العصابية والذهانية والاضطرابات السلوكية، ط لئن

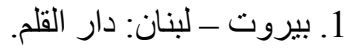

8- الزر اد، فيصل محمد خير. (2000). الأمراض النفسية_جسدية أمراض العصر، ط 1. بيروت:

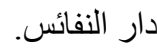

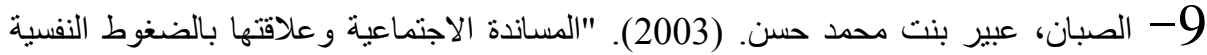

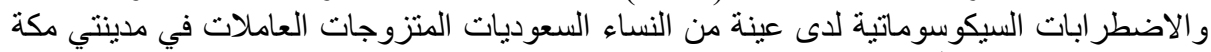

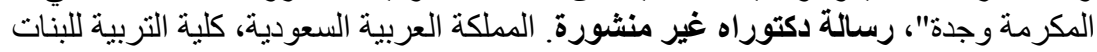

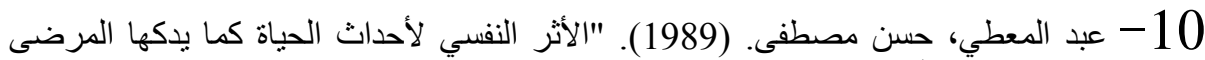

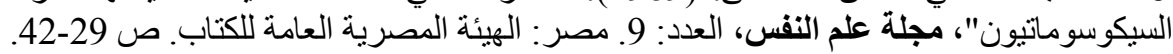


11 - عويضة، كامل محمد محمد. (1996). الصحة في منظور علم النفس، ط 1. بيروت: دار

$$
\text { الكتاب العلمي. }
$$

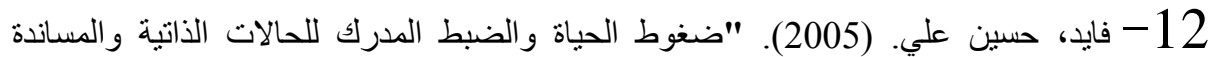

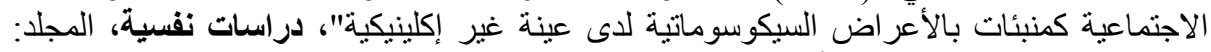

15، العدد: 1، القاهرة: رابطة الأخصائيين النفسين المصرية رانم. ص ص 5- 53.

13- القذافي، رمضان محمد. (1999). علم النفس الفيزيولوجي. الإسكندرية: الدكتب الجامعي

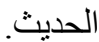

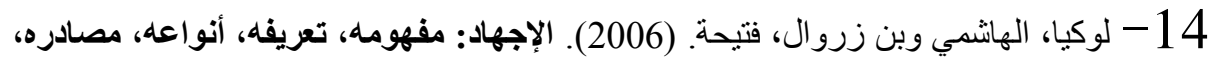

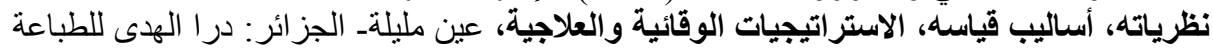
و النشر و التوزيع.

15 - مارنن، بول. (2001). العقل المريض، ط1، ترجمة عبد العلي الجسماني. بيروت،لبنان:

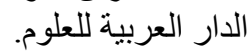

16 - محمود، عبد اله جاد. (2006). السلوك التوكيدي كمتغير وسيط في علاقة الضغوط النفية النفسية بكل من الاكتثاب والعدوان، المؤتمر العلمي الأول لكلية التربية النو عية. جامعة النيط المنصورة.

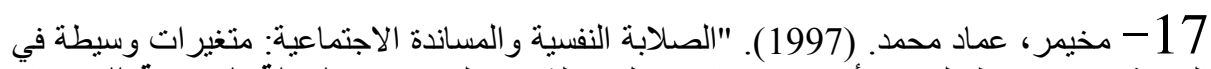

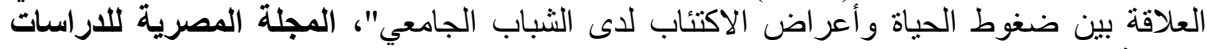

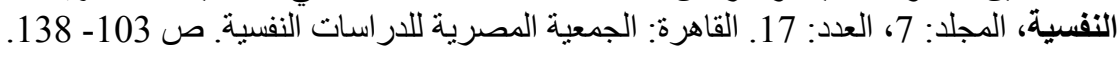

18- معاليم، الح. (2008). محاضرات في الأمراض النفس الجسدية. الجزائر : ديوان المطبو عات

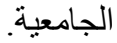

19- مقابلة، نصر يوسف. (1996). "العلاقة بين مركز الضبط و الاحتراق النفسي لدى عينة من

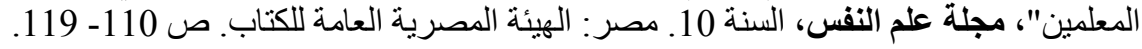

20- موسى، رشاد علي عبد العزيز. (2001). أساسيات الصحة النفسية والعلاج النفسي، ط ط 1.

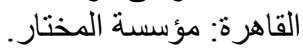

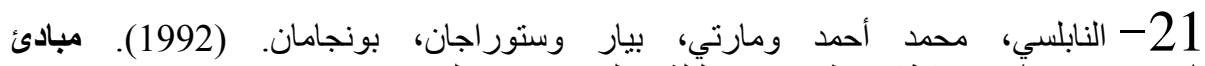
البسيكوسوماتيك وتصنيفاته، ط 1. عين مليلة - الجز ائر : دار الهذى.

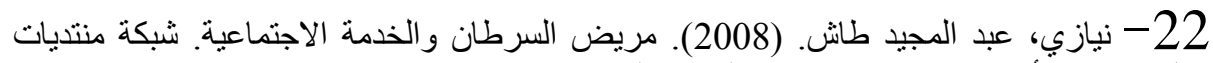
قبيلة مطير، الأقسام الاجتماعية، منتدى الطب والحئ والحياة.

.(2010 /11/23)http://www.mutirr.com/vb/archive/index.php/t-4453.html

23- هيلز، ديانا وهيلز، روبرت. (1999). العناية بالعقل والنفس، ط 1، تعريب و اقتباس وتقديم عبد العلي الجسماني. بيروتـ لبنان: الدار العربية للعلوم.

24- Armstrong, Karen Andera.(2007). "The relationship of health literacy and locus of control to medication compliance in older adult Africans Americans", Gerontology Theses. Pape7. 
http://digitalarchive.gsu.edu/geontology these/7

$(19 / 01 / 2011)$

25- Bennett, Paul \& Norman, Paul \& al. (1998). "Beliefs About Alcohol Health Locus of Control, Value for Health and Reported Consumption In Representative Population Sample Health", Education Research, Vol. 3, No. 1.

26- Davison, G. C. \& Neale, J. M. (1996). Abnormal Psychology Sixth. New Yourk.

27- Herber, A. \& Rayon, R. (1984). Psychology of adjustment. New York: The Dorsey Press. 